\title{
Uma "Experiência sôbre Educação de Base para Trabalhadores"
}

\author{
Inezil Penna Marinho (1) \\ (Técnico de Educação do Ministério da Edu- \\ cação e Cultura)
}

\begin{abstract}
O "Cursos de Educação de Base para Trabalhadores", instituidos em 1954 pela Comissão do Impôsto Sindical (CIS), órgão mantido pela contribuição compulsória de um dia de salário de cada trabalhador, enquadram-se no setor de Educação de Adultos, apresentando, no entanto, particularidades que merecem ser divulgadas e cujo conhecimento poderá ser útil aos que se defrontem com problema semelhante.
\end{abstract}

O Brasil é um país que apresenta elevado índice de analfabetos e tal se deve principalmente a que, com a extinção do trabalho escravo, milhões de indivíduos incultos foram lançados à vida social do país, sem que, para isso, estivessem intelectualmente preparados. Assim, o govêrno da República, recebeu do Império uma herança que traduz complexo problema e para cuja solução tem envidado os maiores esforços.

A educação é modernamente conceituada como processo concomitantemente individual e social; individual porque suscita, desenvolve e aprimora as qualidades sômato-psíquicas de cada ser humano e social porque o integra na comunidade, tornando-o útil a si mesmo e aos seus semelhantes. O desajustamento social procede, consequentemente e em grande parte, da deficiência com que possam atuar os processos educativos, permitindo a instalação de um círculo vicioso em que a ignorância gera a miséria e a miséria perpetua a ignorância.

Nas observações que temos realizado, chegamos à dolorosa conclusão de que, em certas comunidades de trabalhadores, a quantidade de analfabetos se representa assustadoramente por $90 \%$ de seus membros, caracterizandose o analfabetismo como fator principai do baixo padrão de vida, quase miserável, com que se apresentam tais populações. A recuperação social dessas centenas de milhares de seres humanos é medidia que se impõe como obrigação precípua do Estado e das instituições que se identificam por uma nação supletiva, quer no âmbito nacional como a CIS, quer no internacional como a UNESCO.

(1) O autor foi Assessor Técnico para Assuntos de Educação de Trabalhadores da Delegação Brasileira à VIII Reunião Geral da UNESCO, realizada recentemente em Montevideo, tendo apresentado, por intermédio do Dr. Paulo Berredo Carneiro, Chefe da Delegação Brasileira, uma comunicação sôbre o assunto. 
A UNESCO é uma organização criada para difundir Educação, Ciência e Cultura, mas as duas últimas serão impossiveis sem a base que a primeira possa oferecer; em consequência, a Educação de Base deve figurar entre as mais importantes preocupações da UNESCO dentro do seu elevado programa de dar ao homem o direito de pensar livremente e, mais do que isso, de poder exprimir o seu pensamento, libertando a vida espiritual de dogmas, preceitos ou preconceitos que o possam jungir ao temor que a ignorância das causas de cada fato ou fenômeno determina.

O Brasil tudo tem feito no sentido de resolver, o mais ràpidamente possível, o cruciante problema do analfabetismo, que tanto o aflige e entrava seu progresso. Assim, na esfera governamental, o Ministério da Educação e Cultura leva a efeito a Campanha Nacional de Educação de Adultos, instituída pelo Prof. Lourenço Filho há quase uma década; milhares de classes são mantidas por esta Campanha em diferentes pontos do país, procurando, numa ação supletiva, envolver os que escaparam à rêde escolar no tempo oportuno. No domínio da iniciativa privada, o Serviço Social da Indústria (SESI), instituição de caráter patronal, também pode contar às centenas os cursos de educação de adultos que mantém com resultados bastante animadores.

Em 1953, tivemos o ensejo de participar da Reunião de Peritos em Educação de Trabalhadores, levada a efeito no Chateau de la Breviére, em SaintJean, aux-Bois (France), sob os auspícios da Unesco, e no ano passado, colocando em prática os conhecimentos ali adquiridos, foram instalados os primeiros "Cursos de Educação de Base para Trabalhadores", patrocinados pela Comissão do Impôsto Sindical, o que significa dizer mantidos com a contribuição compulsória correspondente ao salário de um dia de cada trabalhador, qualquer que seja a sua categoria profissional e sindicalizado ou não; em última análise, os cursos de educação de base para trabalhadores são mantidos pelos proprios trabalhadores, que assim, juntam o seu esfôrço ao do govêrno e ao dos órgãos patronais.

Os referidos cursos, embora em pequeno número (não chegavam a 50 ), apresentaram resultados bastante animadores, funcionando como verdadeiros centros experimentais de Educação de Base e possibilitando melhor compreensão das necessidades reais do trabalhador e conhecimento mais profundo das reações psíquicas que determinam o seu comportamento social; foram instalados nas sedes das entidades sindicais ou associações profissionais, diretamente animados e fiscalizados pelos respectivos responsáveis, com professor de comprovada competência escolhido na própria localidade. Os cursos de primeiro nível, consistiam apenas em leitura, escrita e contas e objetivavam, com a duração de dez mêses, ensinar o trabalhador a ler, escrever e fazer contas (2) de modo a satisfazer às suas imediatas e prementes necessidades. Os

(2) O trabalhador analfabeto não deseja "aprender aritmética"; êle quer "aprender a fazer contas", pois em tôrno da palavra "contas", gira todo o seu interêsse econômicofinanceiro. No fim do mês, êle tem "contas" para pagar, no trabalho êle tem "contas" quando se despede ou é despedido tem de "fazer as contas". O atual "Caderno de Aritmética", distribuído pela Campanha Nacional de Educação de Adultos, pode-

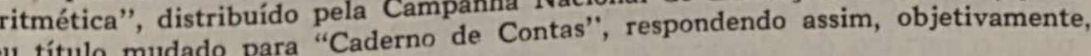
aos interêsses imediatos do trabalhador. 
cursos de segundo nível, também com a duração de dez mêses, ainda não instalados, ministrarão conhecimentos indispensáveis relacionados à vida profissional, ao lar e a comunidade, procurando converter o trabalhador em um cidadão perfeitamente cônscio de seus deveres e direitos, integralmente ajustado aos interêsses e ideais da comunidade. A êste respeito vale considerar que o índice elevadíssimo de analfabetos (mais de $80 \%$ ) aponta a razão precípua pela qual não pode o trabalhador ser politizado, ressalta o motivo que o impede de se transformar em verdadeiro cidadão e assim influir sôbre os destinos do país com o exercício de um direito que lhe tem sido até agora negado: o direito de votar, de exprimir a sua vontade política.

Os "Cursos de Educação de Base para Trabalhadores", em lugar dos antigos "Cursos de Alfabetização", representam um avanço no domínio da recuperação social do trabalhador analfabeto. A elevada percentagem de evasão anteriormente verificada nos chamados "Cursos de Alfabetização", pois em cada cem trabalhadores menos de dez concluiam os estudos previstos, aconselhou cuidadosa investigação sôbre o assunto. Analisando as causas determinantes do fenômeno, verificamos que, na maioria das vêzes, os trabalhadores, embora adultos, homens calejados pelo trabalho rude, eram tratados como crianças, provocando-se em seu espírito uma reação negativa que os afastava dos chamados "Cursos de Alfabetização". Em primeiro lugar, o adulto não gosta de -dizer que "está aprendendo a ler", que "está sendo alfabetizado" ou que "está matriculado no curso de alfabetização"; mas se sente orgulhoso quando afirma estar matriculado no "Curso de Educação de Base para Trabalhadores". As carteiras escollares, via de regra incômodas para o seu tamanho, fazem-no "prisioneiro", como se fôsse uma criança, desagradando-o. As "cartilhas", usadas para a alfabetização, estão inpregnadas de um sentido pejorativo que provoca retração. Por outro lado, os cadernos de caligrafia, que estavam sendo adotados, usavam letra de pé quando o adulto, o trabalhador braçal, encontrará na escrita inclinada a correspondência de suas necessidades; o antebraço apoiado the permite melhor domínio dos movimentos da mão, aumentando a precisão de que carece para reproduzir o contôrno das letras ou manter o alinhamento das palavras. Em consequência de tais observações e para assegurar o êxito dos cursos planejados, foram adotadas as seguintes providências:

a) substituição da expressão "Curso de Alfabetização" por "Curso de Educação de Base para Trabalhador";

b) funcionamento dos referidos cursos nas entidades sindicais, séde de associações profissionais ou em locais especialmente obtidos para êsse fim, evitando-se os grupos escolares ou escolas primárias, como vinha ocorrendo;

c) substituição das carteiras escolares por mesas para pequenos grupos de 8,10 ou 12 trabalhadores, onde êles se sintam com liberdade de movimento e em situação semelhante às que normalmente ocorrem em sua vida, como quando estão em casa ou participam de uma reunião; tais mesas apresentam múltipla utilidade, servindo também para os Cursos de Costura, para as reuniões sindicais, para os cursos de desenho arquitetônico (mantidos por alguns Sindicatos dos Trabalhadores na Indústria da Construção e do Mobiliário), para o serviço de almoços ou " cook-tail"; quando não estão em uso, poderão 
ser desarmadas e encostadas a uma parede, economizando espaço de que quase sempre carecem as entidades sindicais;

d) substituição das habituais "cartilhas" pelos "Guias de Leitura";

e) substituição dos cadernos de caligrafia de letra de pé pelos de letra inclinada (própria para adultos).

Há ainda uma observação que vale ser ressaltada: embora a percentagem de analfabetos entre os trabalhadores seja grande, as entidades sindicais respondiam negativamente quando consultadas sôbre se desejavam cursos de alfabetização em suas sédes. E era preciso investigar as verdadeiras causas dessa formal recusa; a conclusão a que se chegou merece ser divulgada

As sédes das entidades sindicais, sobretudo do interior do país, são modestas e ocupam uma ou duas salas; assim, quando o sindicato manifestava o desejo de ter em sua séde um "curso de alfabetização", a instituição responsável pela iniciativa enviava-lhe dez ou quinze carteiras que atopetavam o espaço útil e impediam o regular funcionamento de sua vida associativa; os interêsses de centenas de associados ficavam prejudicados por 15,20 ou 30 que "estavam aprendendo a ler". E, pouco a pouco, os sindicatos se tornaram inimigos dos "Cursos de Alfabetização", que ameaçavam paralizar a sua vida associativa; mas aquilo que, na verdade, os sindicatos não queriam eram as carteiras, muito embora afirmassem não desejar os "Cursos". A solução do problema, portanto, era simples: bastava eliminar dos cursos as carteiras; e isto foi feito, providenciando-se a sua substituição pelas mesas já citadas. Hoje os sindicatos são os primeiros a solicitar a instalação dos "Cursos de Educação de Base para Trabalhadores", com o que obtêm as referidas mesas de múltipla utilidade. E assim um aspecto negativo foi transformado em fator positivo.

Os "Cursos de Educação de Base para Trabalhadores", estão funcionando em diferentes cidades do Brasil, com classes de trinta alunos, que recebem doze aulas por mês durante um período de 10 meses, totalizando portanto 120 aulas, com a duração de 90 minutos cada.

Convém finalmente ressaltar que a presente experiência, de resultados bastante promissores, inspirou-se nas idéias e recomendações da Reunião de Peritos em Educação de Trabalhadores promovida pela UNESCO, em 1953, no Chateau de la Breviére, Saint-Jean-Aux-Bois, France.

Ainda a respeito do assunto "Educação de Base para Trabalhadores", a Delegação Brasileira, por intermédio de seu Chefe, o Dr. Paulo Berredo Carneiro, apresentou o seguinte Projeto de Recomendação, aprovado pelo plenário da VIII Reunião Geral da UNESCO:

"Considerando que a UNESCO tem promovido sucessivos estágios para preparar peritos em educação de base para trabalhadores, seguidos de reuniões para a discussão dos problemas que lhe são correlatos;

Considerando mais que muitos dêsses peritos regressam aos seus países de origem e não têm a oportunidade de aplicar os conhecimentos adquiridos; 
Considerando ainda que, em consequência, a ajuda técnica concedidat pela UNESCO não é devidamente aproveitada;

Considerando finalmente que alguns peritos, embora consigam aplicar as técnicas aprendidas, não informam sôbre os resultados alcançados;

A oitava reunião geral da UNESCO resolve recomendar aos países membros interessados no assunto que:

a) organizem "Cursos Experimentais de Educação de Base para Trabalhadores", aproveitando para tal fim o pessoal que tenha participado dos estágios e reuniões já promovidos pela UNESCO;

b) solicitem ajuda técnica para a organização dos referidos cursos, caso não disponham do pessoal necessário;

c) informem sôbre os resultados alcançados, esclarecendo as técnicas empregadas".

\section{SUMMARY}

1. Courses of general education for workers created in 1954 as a part of the federal adult education programme. General aim of the courses: social rehabilitation of workers through fundamental education.

2. Social and economic causes of illiteracy in Brazil. The National Campaign fot Adult Education; its ten years of existence, its achievements. The Industry Social Service (SESI), an institution maintained by the employers; objetives and functions.

3. The courses of 1954 described. Less than fifty in number. Their character of experimental centres of general education. Their headquarters: the premises of trade unions or of several occupational associations. Their staff mostly composed of local instructors Lenght of the courses: ten months. Their contents: the three $R$ 's besides vocational education and guidance, home and community life, citizenship.

4. Ordinary elementary courses for adult education, criticized. The psychological mistake of treating adults as if they were children or adolescents. The necessity of changing the name "courses for illiteratfes" into "courses of general education for workers". Classes should never assemble in primary schools. Tables as classroom furniture not desks.

5. The Project of Recommendation presented by the Brazilian Delegation before the Assembly of the 8th General Meeting of the Unesco towards the institution of experimental courses of general education for workers.

\section{MARCHA CONVERGENTE DA ADMINISTRAÇÃO PÜBLICA E DA PARTICULAR}

"A perspectiva mundial contemporânea revela um processo de avizinhamento da administração particular com a administração pública; outrora separadas por barreiras inequívocas, hoje se aproximam uma da outra, como se estivessem em vias de fusão completa."

Benedito Silva

Confronto entre a administração pública e a administração particular. 